\title{
A comparative analysis of the work values of Greece's 'Millennial' generation
}

Emmanouil F. Papavasileiou \& Sean T. Lyons ${ }^{\mathrm{b}}$

${ }^{\mathrm{a}}$ Department of Management, Exeter University, Exeter, UK, ${ }^{\mathrm{b}}$ College of Management and

Economics, University of Guelph, Guelph, Canada

To cite this article: Emmanouil F. Papavasileiou \& Sean T. Lyons (2015) A comparative analysis of the work values of Greece's 'Millennial' generation, The International Journal of Human Resource Management, 26:17, 2166-2186, DOI: 10.1080/09585192.2014.985325

To link to this article: http://dx.doi.org/10.1080/09585192.2014.985325

Published online: 01 Dec 2014.

Abstract: This study adds to the growing body of international evidence concerning the millennial generation (i.e. those born after 1980), by documenting the work values of millennial-aged undergraduate students ( $\mathrm{N}=649$ ) in Greece, using an adapted version of the Lyons Work Value Survey. Our results show that millennial-aged Greeks place most importance on intrinsic and social aspects of work, and less importance on extrinsic and prestige values. We statistically compare our results to those of published studies of millennial-aged respondents from other countries and find that Greek respondents hold a unique work value profile, although they demonstrate some similarities to counterparts in other countries. Our findings do not clearly support the notion of a 'global youth generation', as young people in various countries hold different work value priorities. This suggests that employers seeking to recruit, engage and retain young workers internationally must tailor their offerings to the specific cultural context.

Keywords: cross-national comparison; generational identity; Greece; Millennials; work values

\section{Introduction}

In many developed countries, cohorts of older employees are moving into retirement, requiring employers to attract and retain young talents and to facilitate the transfer of knowledge and skills to younger workers (Cogin, 2012; Taylor, 2005; Twenge, Campbell, Hoffman, \& Lance, 2010). Successfully addressing these human resource $(H R)$ objectives will require a full understanding of the younger generation's work values - their fundamental beliefs about what is important and desirable in their working lives - which underlie a number of HR outcomes, including work motivation, employee recruitment, performance management, employee engagement and retention (Chu, 2008; Dose, 1997; Hansen \& Leuty, 2012; Lyons, Higgins, \& Duxbury, 2010).

Today's young workers, who have been referred to variably as Millennials, Generation $\mathrm{Y}$ and GenMe (Cogin, 2012; Tissen, Lekanne Deprez, Burgers, \& van Montfort, 2010; Twenge et al., 2010), have been the subject of much international research attention in recent years. A growing body of international research documents differences in the work values of millennial-aged workers (i.e. those born in 1980 or later) relative to their predecessors (Lyons \& Kuron, 2013; Parry \& Urwin, 2011; Twenge, 2010). To date, much of this research has emanated from English-speaking countries (i.e. the USA, Canada, Australia, the UK and New Zealand). Researchers have begun to examine the work values of today's 
young workers in other countries, but the applicability of the 'millennial' prototype across cultural contexts remains unclear. Although some commentators have suggested that Millennials are the first 'global generation' (Edmunds \& Turner, 2005), with a generational consciousness that transcends national culture, there is insufficient evidence to support or refute this claim.

The present study provides the first evidence of the work values of millennial-aged Greeks, adding to the growing body of international research on this generation. Given the unique social and historical conditions that shaped this generational cohort in Greece, it is important to document contemporary Greek work values as a benchmark for future research in the country. We address the inconsistency of work values measurement across studies by introducing an adapted work values scale that succinctly measures four underlying types (i.e. intrinsic, extrinsic, social/altruistic and prestige). This provides a more theoretically consistent conceptualization of work values that reveals broader patterns that can be of practical use to HR professionals. We then employ the four work values typology to compare the scores of millennial-aged Greeks to those of their counterparts in other countries, as documented in previously published research. This allows us to test the validity of the 'global generation' hypothesis. To our knowledge, this is the first review of international findings concerning the work values of millennial-aged respondents from around the world.

\section{Work values}

Work values are one's beliefs about the relative desirability of various aspects of work (e.g. pay, autonomy, working conditions) and work-related outcomes (e.g. accomplishment, fulfilment, prestige) (Elizur, 1984; Lyons et al., 2010). According to career development theory, work values emerge in early adolescence as expressions of general human values (Super, 1957) and are tested and refined throughout adolescence and early adulthood (Porfeli, 2007), becoming more cohesive and relatively fixed (though not immutable) during early adulthood (Jin \& Rounds, 2011). As a central psychological construct in one's orientation towards work, work values are an important predictor of a number of HR outcomes, including job satisfaction (Froese \& Xiao, 2012), organizational commitment (Howell, Kirk-Brown,\&Cooper, 2012), team effectiveness (Bhatnagar \& Tjosvold, 2012), conflict management (Ma, Liang, Erkus, \& Tabak, 2012) and the degree of fit between a person and his or her organization, occupation and work environment (Jin \& Rounds, 2011).

Despite many different labels, measures and conceptualizations, the various aspects included in the work values domain have been shown to fall into four broad categories: (1) intrinsic work values, which relate to the pursuit of personal growth such as advancement and independence; (2) extrinsic work values, which reflect more concrete work outcomes such as pay and security; (3) social or affective work values, which capture emotions and feelings as well as social experiences and roles such as esteem, interpersonal relationships and social contribution; and (4) prestige or power work values, which refer to aspects of personal success and dominance over others such as recognition and authority (Chen \& Kao, 2012; Hirschi, 2008; Jin \& Rounds, 2011; Lyons et al., 2010; Porto \& Tamayo, 2007; Ros, Schwartz, \& Surkiss, 1999).

\section{The Millennial generation}

A generation can be defined as a group of individuals born within the same historical and sociocultural context, who experience similar formative experiences and therefore develop unifying commonalities (Mannheim, 1952). The term 'Millennials' was coined by Strauss and Howe (1991), who argued that the confluence of demographics, life cycle development, parenting norms and social crises of the late twentieth century would produce a unique generation of civic-minded adults in the new millennium, who would rise to the challenge of restructuring society's institutions. In contrast to this prediction, 
recent depictions of Millennials have painted them as self-centred, entitled, narcissistic, materialistic and demanding, embodying a 'what's in it for me?' attitude in the workplace (Cogin, 2012). They are said to be the product of over-protective 'helicopter' parenting (Glass, 2007) and are commonly presented as disloyal job-hoppers who are in continuous search of better opportunities and compensation (Chaudhuri \& Ghosh, 2012). They are viewed as ambitious, seeking opportunities to contribute immediately and to have their voices 'heard' (Murphy, 2012). They are said to question authority (Crumpacker \& Crumpacker, 2007) and to seek training and development opportunities in order to bolster their employability (Taylor, 2005). More positively, they are viewed to be creative and skilled at multitasking, technologically savvy and highly connected socially (Society for Human Resource Management, 2005). Finally, they are said to value flexibility in their work arrangements and to give lifestyle and leisure activities precedence over work (Shaw \& Fairhurst, 2008).

Although these characterizations are based on social and historical conditions relevant to North America, particularly the USA, researchers and commentators have applied them to post-1980 birth cohorts in a number of other societies (e.g. Lub, Bijvank, Bal, Blomme, \& Schalk, 2012; Wils, Saba, Waxin, \& Labelle, 2011; Zupan, Kas`e, Ras`kovic', Yao, \& Wang, 2013). The degree to which these attributes of Millennials' identity can be exported to various cultures is a matter of debate. Vincent (2005, p. 584) argued that the formative influences that shape generational identity are 'local and specific and emergent from personal biography and family and community situation', suggesting that generational identity is a product of one's specific cultural context. This perspective is rooted in the foundational generation theory of Mannheim (1952), which posited that generations become actualized in the face of historic and social conditions endemic to each national context. The counterargument, mentioned above, is the 'global generation' hypothesis advanced by Edmunds and Turner (2005), which posits that national boundaries are less important to generational identity now than in the late 1920s when Mannheim's original thesis was first published. Instead, they argue that the formative influences shaping modern generational identity, such as technology, economics and cultural trends, transcend national borders, perhaps forging a common millennial generational identity across the developed world.

The present study adopts a values-based approach to test the 'global generation' hypothesis using the case of Greek Millennial generation. In particular, we employ the common four work values types (extrinsic, intrinsic, social and prestige) to directly compare extant findings of millennial-aged workers and students from 11 countries: Greece, Slovenia, Switzerland, Germany, Japan, China, Taiwan, Canada (including Quebec), New Zealand, UAE and Brazil. To facilitate comparison, we group these countries using the cultural clusters defined by the Global Leadership and Organizational Behaviour Effectiveness (GLOBE) research programme (House et al., 1999). The GLOBE studies involved 170 researchers who collected data concerning leadership attributes, practices and values from over 17,000 managers in 62 nations. Based on their results, they identified 10 cultural clusters: Southern Asia, Confucian Asia, Sub-Saharan Africa, Arab, Latin Europe, Eastern Europe, Germanic Europe, Nordic Europe, Anglo and Latin America (Gupta, Hanges, \& Dorfman, 2002).

\section{Millennials' work values in the Greek context}

Greece has often been referred to as a geographical and cultural 'bridge' between East and West (Galanaki \& Papalexandris, 2013). The GLOBE studies placed Greece within the Eastern Europe cluster, with such countries as Albania, Georgia, Hungary, Kazakhstan, Poland, Russia and Slovenia (Gupta et al., 2002). Work values evidence from the Eastern European cluster is scarce and no empirical evidence exists from Greece. The only existing work values data are Zupan et al.'s (2013) study of Slovenian business students, which found that millennial-aged Slovenians placed higher importance on extrinsic 
and intrinsic work values, whereas social and prestige work values were least important (see Table 1). The present study is the first to document the work values of millennial-aged Greeks.

From a sociopolitical perspective, the millennial-aged cohort in Greece appears to have been critically influenced by two effects of the 'westernization' or better the 'modernization' process imposed by governments after 1996. On the one hand, Greece benefited from opportunities provided by European Union funding from hosting the 2004 Olympic Games and the accession in the European Monetary Union. On the other hand, the country was plagued by an opportunistic mentality towards these benefits, which is represented by the expressions 'volema' (to get into, or remain in, a situation/position that works for one self without considering others), 'meso' (the medium - usually a political figure - who helps to accomplish what needs to be accomplished), 'rousfeti' (clientalism) and 'ohadelfismos' (to 'get by' without caring about tomorrow) (Chalari, 2012, pp. 4-5). This generation has also enjoyed a highly permissive regime that has provided them an unlimited time frame for the completion of studies (Katsikas \& Panagiotidis, 2011). However, an increasing number of young Greeks must now work while studying, having lost traditional parental support due to parents reduced incomes or unemployment. Younger members of the cohort are experiencing a more complicated, demanding and challenging social reality, which is characterized by mobility, uncertainty and difficulty in projecting the future. Thus, recent research evidence depicts millennial-aged Greeks as agentic, aware of the importance of contributing to social change and capable of shifting their mode of thought to enact such change (Chalari, 2012).

Given the limited empirical evidence from the Eastern Europe cluster, the complex mixture of eastern and western influences within Greek culture and the modernizing influences affecting Greece in recent years, it is impossible to hypothesize what the work values of millennial-aged Greeks will be. As such, it is a major objective of the present study to document the work value priorities of millennial-aged Greeks, as reflected in the following research question:

RQ1: What are the work value priorities of millennial-aged Greeks?

\section{Millennials' work values around the world}

Table 1 describes the results of 22 studies from 17 different countries that measured the work values of millennial-aged workers and students. The samples are quite heterogeneous, ranging from high school students to employees in various industries (e.g. construction, hospitality, pharmaceuticals) to respondents to general social surveys.

Furthermore, the timing of data collection varies, with studies published as early as 2005 and as late as 2014. These variations, along with differences in the way that work values are measured among studies, make it difficult to generalize and interpret the results. Therefore, to facilitate comparisons across countries, we have organized the results according to the cultural clustering framework proposed by the GLOBE project. These cultural clusters are applicable to the study of work values, which are specific manifestations of the broader values that are expressed as a component of national culture (Ros et al., 1999).

Overall, there appear to be few consistent trends across cultures. Although there is internal consistency within some clusters, such as the Latin America cluster, the Confucian Asia cluster and the Germanic Europe cluster, the Anglo cluster, representing Canada, the USA, Australia, New Zealand and the UK shows great variation in the rank ordered importance of various work values among countries and even within countries across samples and measures. The one generalization that appears to be valid is that prestige and status values are among the lowest in importance in samples of millennial aged respondents across various countries. All three of the other major categories of 
work values were most important to respondents in one or more studies: extrinsic work values in six countries, including Canada (Lyons et al., 2012), the USA (Chen \& Choi, 2008), Taiwan (Chen \& Kao, 2012), Japan (Takase, Oba, \& Yamashita, 2009), China (Zupan et al., 2013) and Slovenia (Zupan et al., 2013); intrinsic work values in four countries, including the USA (Real, Mitnick, \& Maloney, 2010; Twenge et al., 2010), Australia (Taylor, 2012), Brazil (Macedo, 2012; Porto \& Tamayo, 2007) and Norway (Sillerud, 2011); and social/altruistic work values in three countries, including Canada (Lyons, Duxbury, \& Higgins, 2005), New Zealand (Cennamo \& Gardner, 2008) and Malaysia (Infeld, Adams, Qi, \& Rosnah, 2010).

The 'global generation' hypothesis (Edmunds \& Turner, 2005) suggests that the post- 1980's generation should exhibit relatively homogeneous values across cultural contexts. These values should be expressed in the workplace as common work-related values (Ros et al., 1999). The evidence presented in Table 1 seems to counter this hypothesis, as the work value priorities vary notably across samples. Unfortunately, given the variation in measures, samples and work value factors across studies in Table 1, it is impossible to make definitive 'apples to apples' comparisons based on their findings. In the present study, we compare the work values of millennial-aged respondents from various nations using a common work values typology (i.e. extrinsic, intrinsic, social and prestige work values) to test the global generation hypothesis, which is stated as follows:

Hypothesis 1. The work values of millennial-aged people from different countries will be homogeneous.

\section{Methodology}

Sample

The subjects were 649 Greek undergraduate students born in 1980 or later (i.e. corresponding to the ages of the Millennial cohort; Ng, Schweitzer, \& Lyons, 2010; Tissen et al., 2010). During the fall of 2011, 700 questionnaires were randomly distributed to students in all seven of the Tourism Management programmes offered in Greece's Technological Educational Institutes. Questionnaires were completed anonymously and voluntarily. As an inducement, a small donation to a children's foundation was made for each completed survey. Student samples are commonly used in work values research, as is evident in Table 1. Although work values have been shown to solidify and become more consistent with increasing work experience (Johnson, 2001; Porfeli, 2007), recent meta-analytic evidence from longitudinal studies of work values (Jin \& Rounds, 2011) shows that the rank order of work values (as opposed to the absolute strength of importance ratings) is consistent across the lifespan from age 12 onwards, with the greatest stability occurring after age 22 . Thus, we deemed this sample, which ranges in age from 18 to 22 , to be an appropriate sample of millennial-aged respondents. Almost half of the students $(\mathrm{N}=310,48 \%)$ indicated that they were employed during the period of the survey. The final sample of 649 participants ( $92 \%$ response rate) included 357 women (55\%) and 292 men (45\%).

\section{Measure}

Work values were measured using a modified version of the Lyons Work Values Survey (LWVS; Lyons et al., 2010). Extant work values research lacks consistency in the range of items used to measures the construct, with many studies using idiosyncratic lists of work aspects (such as those included on employee satisfaction surveys) and deriving work values typologies inductively through data-driven approaches such as principle components analysis. As a result, factors that are similar in nature are often interpreted and named differently across studies, making it difficult to compare results (Leuty \& Hansen, 2011). Although validated measures exist, such as the Minnesota Importance 
Questionnaire (Rounds, Dawis, Lofquist, \& Weis, 1981), Super's Work Values Inventory Revised (Zytowski, 2004) and Manhardt's (1972) Work Values Inventory, research suggests that none of these measures fully captures the full domain of the construct (Leuty \& Hansen, 2011). The LWVS was used in the present study because it has been shown to measure all four types of theorized work values (i.e. intrinsic, extrinsic, social and prestige values) (Lyons et al., 2010) and has been used in a number of previous studies (see Table 1). The full version of the LWVS contains 37 items and is therefore somewhat onerous for respondents to complete. Furthermore, it contains some items that do not load reliably on the four factors (Lyons et al., 2010) and is unbalanced, with most of the items loading on two of the factors. We therefore developed a more parsimonious and balanced 20 -item adaptation of the LWVS for the present study, which includes 3 new items that support the underlying structure of the LWVS that were not included in its original form (items are shown in Table 2). The addition of new work aspects to the original set is consistent with the design of the LWVS, as they provide added evidence of the interrelations of various work aspects within the work values domain (Lyons et al., 2010).

As per the LWVS instructions, participants were asked to rate the degree to which each work outcome would be a 'top priority' when selecting a potential job or deciding to remain in their job on a six-point scale ( 1 : highly unlikely; 6 - highly likely). By capturing the relative priority that respondents place on each item in the context of selecting or staying in a job, the instrument integrates both the hierarchical nature of values (Schwartz, 1994) and the notion of value trade-offs in selecting job-related behaviours (Lyons et al., 2005).

\section{Procedure}

To ensure the validity of the adapted 20-item LWVS measure, we examined its underlying structure through both exploratory factor analysis (EFA) and confirmatory factor analysis (CFA). Data were randomly divided into two subsamples, which were deemed sufficiently large for separate analysis (Fabrigar, Wegener, MacCallum, \& Stahan, 1999; Nunnally, 1978; Tabachnick \& Fidell, 2007). Data from the first subsample $(\mathrm{N}=328)$ were analysed using EFA. There is substantial theoretical and empirical evidence to suggest that the four types of work values are correlated with one another (cf. Lyons et al., 2010; Ros et al., 1999). Therefore, the restriction of uncorrelated factors that is imposed by orthogonal rotations is unwarranted and can lead to misleading results (Fabrigar et al., 1999). Common factor analysis with principal axis factoring and oblique rotation was therefore used, which allowed the factors to be correlated (Fabrigar et al., 1999; Ford, MacCallum, \& Tait, 1986). As shown in Table 2, a four-factor structure was identified by examining the scree plot and retaining factors with eigenvalues greater than one (Kaiser, 1970). One item, related to work schedule had loadings lower than 0.50 on all factors, and three other items, 'influence', 'interest' and 'social contribution', crossloaded on multiple factors and were therefore omitted from further analysis (Tabachnick \& Fidell, 2007). EFA of the set of the 16 remaining work aspects produced a more meaningful and interpretable solution that explained $58.3 \%$ of total variance. All items had loadings greater than 0.60 on a single factor with communality scores exceeding 0.50 , providing additional evidence of convergent validity (Fabrigar et al., 1999).

The first factor contained four work aspects related to intrinsic work values related to the psychological benefits of work (i.e. innovation, using one's abilities, autonomy, attachment). The second factor was composed of four items expressing extrinsic work values related to instrumental work conditions (i.e. benefits, stress avoidance, earnings, stability). The third factor includes four items that relate to status and prestige (i.e. authority, decision-making, organization, status). The fourth factor included four items related to social work values, reflecting relationships and interactions with 
others (i.e. owner, esteem, colleagues, interaction). All four factors demonstrated high levels of internal reliability with Cronbach's $\alpha$ coefficients exceeding 0.80 (Nunnally, 1978).

CFA was used to examine the goodness of fit of the four-factor structure derived from the EFA, using data from the second subsample ( $N=321)$. CFA results indicated that the 16 -item, four-factor model fit the data adequately $(x 2 / d f=2.06$; Root Mean Square Error of Approximation (RMSEA) $=0.058$; Non-Normed Fit Index (NNFI) $=0.94$; Comparative Fit Index $(\mathrm{CFI})=0.95)$, with all items loading above 0.50 on their designated work values (Tabachnick \& Fidell, 2007). These results confirm the content validity of the four factor solution. Reliability coefficients for the four latent factors in the revised model indicated high internal consistency (i.e. social $a=0.86$, intrinsic $a=0.75$, extrinsic $a=0.83$, prestige $a=0.84$ ). Multiple groups CFA ruled out potential measurement variance related to gender and working status. The fit of two nested models was compared: the model hypothesizing loadings equality among groups and the unconstrained model. The value of the chi-square among the competing models was not significant for either gender $(\Delta x 2=16.7, d f=12, p=0.160)$ or work status $(\Delta \times 2=13.4, d f=12, p=0.341)$, indicating that the four-factor structure applies equally well to men and women and to students and workers.

To address RQ1, we calculated scores for each of the four higher-order work values by averaging each participant's scores on the four aspects of work corresponding to each work value. We then addressed Hypothesis 1 by comparing the work values of Greek Millennials to those of other countries using data from previously published studies that employed the four-factor model of intrinsic, extrinsic, social/altruistic and prestige work values (denoted by * in Table 1). Because different measurement scales were used across these studies, we compared the rank orders of the four work values based on sample means, using Spearman rank order correlations and Kendall's coefficient of concordance (W) as proposed by Harrington (1993). Here, Spearman's rho correlation coefficients denote the degree of agreement among the rankings of each pair of countries. Because the number of items being compared (which constitutes the sample size in this analysis) is small, traditional estimates of significance are not appropriate.

Based on the values provided by Glasser and Winter (1961), coefficients of 0.80 or higher were considered to be significant. In addition, Kendall's coefficient of concordance (W) tests the degree of agreement among three or more rankers in their rankings of a set of common objects. Here, Kendall's $\mathrm{W}$ assessed the degree of agreement in the rank orders of work values among the 12 samples. Hypothesis 1 would be supported if (1) Kendall's W was significant $(p, 0.05)$ and the degree of agreement was at least 'fair' (.0.50) (Schmidt, 1997; Siegel \& Castellan, 1988) and (2) the majority of pairwise Spearman's rho correlations among countries were positive and significant.

\section{Results}

The means, standard deviations and inter-correlations of the work value types are given in Table 3 . In answer to RQ1, intrinsic work values were rated most highly by Greek Millennials (Mean $=5.03, \mathrm{SD}=$ 0.97 ), followed by social (Mean $=4.74, S D=0.95$ ), extrinsic (Mean $=4.54, S D=0.92$ ) and prestige values $($ Mean $=4.51, \mathrm{SD}=1.06)$.

Table 4 shows the results of cross-national comparisons of work values scores from the present study with those of 11 other studies. The test of Hypothesis 1 provided limited support for the global generation hypothesis. Coefficient scores range from 0 (no agreement at all) to 1 (total agreement). Although Kendall's $W$ was significant, it was small ( $W=0.358, p, 0.05)$, indicating weak overall agreement among the rankings of various countries (Schmidt, 1997). Pairwise comparison of the rank order correlations of various samples provided us with more detailed analysis of the patterns of 
agreement among the 12 samples. Coefficients range from 1.0 (i.e. both countries had the same rank order of work values) to -1.0 (i.e. countries have exact opposite rankings). As can be seen in Table 4, of the 66 rank-order correlations between countries, only 24 (36\%) were significantly positive, while $7(11 \%)$ were significantly negative and $35(66 \%)$ were not significant. The bottom rows of Table 4 show the percentages of pairwise rank-order correlations (of 11 possible comparisons) that were significantly positive, significantly negative and not significant for each national sample. These range from a high of $54.5 \%$ positive correlations (Slovenia, Switzerland, Taiwan, Canada and Brazil) to a low of zero positive correlations (UAE). The percentage of negative correlations ranged from $63.6 \%$ (China) to 0 negative correlations (Slovenia, Taiwan and French Canada). Overall, these results do not provide convincing support for the notion of a global generation with respect to work values.

\section{Discussion}

The present study offers insights into the work values of millennial-aged Greeks, adding to the body of evidence concerning the work values of the young generation of career entrants from around the world. Overall, we can conclude that millennial-aged Greeks hold work value priorities that are moderately unique relative to their counterparts in other countries, particularly those placed within Eastern cultural clusters. Their work value priorities were not significantly similar in ranking to millennial-aged respondents from the Confucian Asia cluster or Slovenia (the only other country in the Easter Europe cluster for which data were available). In addition, they held values that were the exact opposite of their counterparts in the UAE (representing the Middle East cluster). However, young Greeks demonstrated work values that were significantly similar to those of their counterparts in Germanic Europe, the Anglo cluster (excluding French Canada) and Brazil (part of the Latin American cluster).

Specifically, millennial-aged Greeks place the greatest priority on intrinsic work values, similar to their counterparts in Germanic Europe and Latin America (as shown in the results presented in Table 1). Social work values were ranked as second highest in importance to millennial-aged Greeks. By comparison, they rank social work values higher than all comparator countries other than New Zealand, where social values ranked highest, and Germany, Japan and China, where social values also ranked second. Greek respondents ranked extrinsic work values third, lower than all comparators other than New Zealand, where they were also ranked third, and Germany, where they were ranked lowest.

Young Greeks placed the lowest priority on prestige work values, similar to millennial aged youth in Slovenia, Switzerland, China, Taiwan, Brazil and the Anglo countries (i.e. Canada, New Zealand). These results suggest that, even in the face of the economic crisis that has affected their generation, millennial-aged Greeks place most importance on the psychological and social aspects of their jobs, and less importance on pay and security. The variety in work value rakings demonstrated in our analyses provides limited support for the 'global generation' hypothesis (cf. Edmunds \& Turner, 2005), which argues that common global influences are forging a youth cohort that shares common values despite geographic separation. Our results suggest that, in the case of work values, millennial-aged respondents from across the world are not highly similar, as evidenced by the relatively small number of significant positive rank-order correlations. In fact, our results suggest that work value priority rankings are not significantly similar within the Eastern European cluster, between Greeks and Slovenians, the Germanic Europe cluster, between Swiss and Germans, the Confucian Asian cluster, between Japanese and Taiwanese or in the Anglo cluster between Canadians and New Zealanders. It is quite possible that the youth cohorts in various countries hold work values that are significantly different than their predecessors, without having work values that are similar to their contemporaries from other countries. Such a pattern of cross-national (i.e. India, South Africa, the USA, the UK), cross- 
generational differences was observed by Deal et al. (2012) with respect to perceptions of leader effectiveness: despite overall non significance of age as a predictor, the youngest cohort in each country tended to hold perceptions that were different from their predecessors and also different from each other. In other words, millennial-aged people from around the world may be united in their divergence from their elders, but little else. It is not possible to draw such a conclusion from the results of the present study. What can be said on the basis of our investigation is that there appears to be no strong evidence for the assumption that work-related millennial stereotypes can be applied to young workers in other cultures.

\section{Practical implications}

The theory of work adjustment (Dawis \& Lofquist, 1984) suggests that when workers perceive a job or employers to provide them with psychological benefits and good opportunities for social interaction, they will perceive a strong fit with their personal values, encouraging them to choose a job with that employer, to be engaged in their work and to choose to stay in that job (i.e. the person-environment fit hypothesis). Our findings suggest that employers seeking to attract, engage and retain young workers must pay attention to cultural variations in work values. Even among young workers, a 'onesize fits- all' approach to HR policies and programmes is inappropriate. Multinational organizations are therefore advised to view their young workers as a heterogeneous group rather than as stereotypical 'Millennials'. Our findings have specific implications for Greek employers seeking to attract and retain young workers: they should emphasize the intellectual and social benefits of the job and organization. It is good news to Greek employers that, in the midst of an economic rebuilding period, young workers are not as focused on pay and benefits as their counterparts in other countries. Employers should endeavour to create jobs and work environments that provide intangible benefits such as variety, creative expression, intellectual stimulation, social interaction and strong work relationships. These are all elements of organizational culture that will attract, engage and retain young workers, even in the absence of pay and prestige.

Nevertheless, taking into consideration the increasing rate of unemployment in Greece, HR professionals are faced with the daunting task of selecting potential employees from a vast pile of applications. Knowing that job applicants have not only a preference for specific aspects of work but also knowledge of their deeper work value patterns allows HR professionals to select those that best fit the values reinforced in the specific work environment and thus reduce costs associated with employee turnover (Hansen \& Leuty, 2012; Lyons et al., 2010). Schneider's (1987) AttractionSelection-Attrition framework suggests that efforts to attract, select and retain the 'right people' are essential to defining the characteristics of an organization. Thus, having an understanding of the predominant values of the millennial generation can help employers to determine whether 'typical' millennial work values are desirable for the organization, and if not, can help them to adjust recruitment and selection processes to target 'non-typical' young entrants.

\section{Limitations and directions for future research}

In this study, we have taken a first step towards comparing Millennials' work values across several cultural clusters. Drawing on contemporary scholarship on the concept of generations, which dictates that generations represent a distinctive and shared set of values, we have argued that a value-based conceptualization is appropriate for cross-cultural comparison. To date, there has been very little consistency in the way that Millennials' work values have been measured from study to study, making direct comparisons very difficult. Extant studies have used different measurement approaches (i.e. ratings versus rankings) and different sets of work value items. Our conceptualization of work values highlights the intrinsic, extrinsic, prestige and social/altruistic four-factor structure as a common 
classification for comparing the work identity of Millennials across different cultural clusters. This structure allows comparisons with previously reported results from the broader managerial literature, provides directions for assessing the work values domain and is more likely to lead to theoretical interpretation of empirical observations pertaining to Millennials identity in the workplace. Future research should seek to replicate the work value structure observed here using different analytic techniques and samples. For instance, the use of smallest space analysis, a non-metric scaling technique that shows patterns of interrelationships among measurement items, would provide additional confidence regarding the extracted findings and their generalizability.

There are four limitations to the present study that should be addressed in future research. First, our sample was restricted to millennial-aged undergraduate students in tourism-related programmes. Although this sample may not be fuller representative of millennial-aged Greeks, it is an important sample, as the tourism sector is a large employer in Greece and it situates our study within a body of literature that commonly draws on respondents from a single sector or industry. Since the tourism sector is disproportionately staffed with millennial-aged workers, our findings can inform HR practices in an important sector of the Greek economy. Future studies of Greek Millennials should examine whether the work values documented here are generalizable to other industries.

Second, we relied on a cross-sectional design, which makes it impossible to assess whether the values of millennial-aged Greeks are likely to shift over time as the cohort ages. Future studies should employ a longitudinal methodology to disentangle cohort based effects from ageing effects among this population. Third, the comparisons we made to extant published data involved differing measures of work values that were collected at different times. As a result, our test of the global generation hypothesis relied on comparison of rank-orders of work value scores, rather than comparing work value scores directly. It should be noted that many of the instruments used in these studies are highly similar in nature, often drawing items from common existing measures of work values. The fact that comparable four-factor structures were identified in studies employing different work value measures speaks to the robustness of this underlying structure. Because the instruments differed in their number of items and their measurement scales, we were unable to compare absolute work value scores across cultures and instead compared the rank-orders of work values. Future research should endeavour to utilize a cross-cultural, cross-generational design that fully standardizes measurement and allows for comparisons of both generational cohorts and national cultures. This would provide a more unequivocal test of the global generation hypothesis.

Finally, extant research provided us with comparative from relatively few countries. Using the GLOBE cultural clusters as a basis for grouping countries based on values may be a valuable framework so long as data from a greater number of countries can be obtained. For instance, our only source of data from the Middle East cluster came from the UAE, which may not be representative of the region because of its relative level of economic affluence. Future research should therefore examine the work values of younger workers from a wider range of national contexts.

\section{Conclusions}

The present study shows that millennial-aged Greeks hold work value priorities that are moderately unique relative to their counterparts in other countries, including Slovenia, its closest neighbour compared in our analyses. Specifically, millennial-aged Greeks placed the most importance on intrinsic work values and social work values, and relatively less importance on extrinsic work values and prestige values. These values most closely resemble those of young workers in Germanic Europe, Canada, New Zealand and Brazil, and are least similar to those of young workers in the UAE and Confucian Asia. The implication of these findings is that, contrary to the 'global generation' hypothesis 
(Edmunds \& Turner, 2005), millennial-aged people around the world are not highly homogeneous in their work values. HR practitioners in various countries must be cautious when interpreting research concerning this generation to ensure that it is indeed applicable to their national context.

\section{Acknowledgements}

The authors acknowledge their gratefulness to Sylia Vitoratou for her assistance with data analysis and Professors Rein de Cooman, Vivian Chen, Juliana Porto and Robert Kase for providing the mean importance scores of work values from their studies.

Disclosure statement

No potential conflict of interest was reported by the authors.

\section{References}

Bhatnagar, D., \& Tjosvold, D. (2012). Leader values for constructive controversy and team effectiveness in India. The International Journal of Human Resource Management, 23, 109-125.

Cennamo, L., \& Gardner, D. (2008). Generational differences in work values, outcomes and person organisation values fit. Journal of Managerial Psychology, 23, 891-906.

Chalari, A. (2012). The causal powers of social change: The case of modern Greek society. Hellenic Observatory. London: London School of Economics.

Chaudhuri, S., \& Ghosh, R. (2012). Reverse mentoring a social exchange tool for keeping the boomers engaged and millennials committed. Human Resource Development Review, 11, 55-76.

Chen, P. J., \& Choi, Y. (2008). Generational differences in work values: A study of hospitality management. International Journal of Contemporary Hospitality Management, 20, 595-615.

Chen, C.-H. V., \& Kao, R. H. (2012). Work values and service-oriented organizational citizenship behaviors: The mediation of psychological contract and professional commitment: A case of students in Taiwan Police College. Social Indicators Research, 107, 149-169.

Chu, K. H. (2008). A factorial validation of work value structure: Second-order confirmatory factor analysis and its implications. Tourism Management, 29, 320-330.

Cogin, J. (2012). Are generational differences in work values fact or fiction? Multi-country evidence and implications. The International Journal of Human Resource Management, 23, 2268-2294.

Crumpacker, M., \& Crumpacker, J. M. (2007). Succession planning and generational stereotypes: Should HR consider age-based values and attitudes a relevant factor or a passing fad? Public Personnel Management, 36, 349-369.

Dawis, R. V., \& Lofquist, L. H. (1984). A psychological theory of work adjustment: An individual differences model and its applications. Minneapolis: University of Minnesota Press.

de Cooman, R., \& Dries, N. (2012). Attracting generation Y: How work values predict organizational attraction in graduating students in Belgium. In E. S. Ng, S. T. Lyons, \& L. Schweitzer (Eds.), Managing the new workforce: International perspectives on the millennial generation (pp. 4263). Cheltenham: Edward Elgar.

Deal, J. J., Stawiski, S., Graves, L. M., Gentry, W. A., Ruderman, M., \& Weber, T. J. (2012). Perceptions of authority and leadership: A cross-national, cross-generational investigation. In E. S. Ng, S. T. 
Lyons, \& L. Schweitzer (Eds.), Managing the new workforce: International perspectives on the millennial generation (pp. 281-306). Cheltenham: Edward Elgar.

Dose, J. J. (1997). Work values: An integrative framework and illustrative application to organizational socialization. Journal of Occupational and Organizational Psychology, 70, 219-240.

Edmunds, J., \& Turner, B. S. (2005). Global generations: Social change in the twentieth century. The British Journal of Sociology, 56, 559-577.

Elizur, D. (1984). Facets of work values: A structural analysis of work outcomes. Journal of Applied Psychology, 69, 379-389.

Fabrigar, L. R., Wegener, D., MacCallum, R. C., \& Stahan, E. J. (1999). Evaluating the use of exploratory factor analysis in psychological research. Psychological Methods, 4, 272-299.

Ford, J. K., MacCallum, R. C., \& Tait, M. (1986, June). The application of exploratory factor analysis in applied psychology: A critical review and analysis. Personnel Psychology, 39, 291-314.

Froese, F. J., \& Xiao, S. (2012). Work values, job satisfaction and organizational commitment in China. The International Journal of Human Resource Management, 23, 2144-2162.

Galanaki, E., \& Papalexandris, N. (2013). Measuring workplace bullying in organisations. The International Journal of Human Resource Management, 24, 2107-2130.

Glass, A. (2007). Understanding generational differences for competitive success. Industrial and Commercial Training, 39, 98-103.

Glasser, G. J., \& Winter, R. F. (1961). Critical values of the coefficient of rank correlation for testing the hypothesis of independence. Biometrika, 48, 444-448.

Gupta, V., Hanges, P. J., \& Dorfman, R. (2002). Cultural clusters: Methodology and findings. Journal of World Business, 37, 11-15.

Gursoy, D., Chi, C. G.-Q., \& Karadag, E. (2013). Generational differences in work values and attitudes among frontline and service contact employees. International Journal of Hospitality Management, 32, 40-48.

Hansen, J. C., \& Leuty, M. E. (2012). Work values across generations. Journal of Career Assessment, $20,34-52$.

Harrington, T. F. (1993). A comparison of work-related values of adolescents from five countries. International Journal for the Advancement of Counselling, 16, 81-87.

Hirschi, A. (2008). Personality complexes in adolescence: Traits, interests, work values, and selfevaluations. Personality and Individual Differences, 45, 716-721.

Hirschi, A., \& Fischer, S. (2013). Work values as predictors of entrepreneurial career intentions: A longitudinal analysis of gender effects. Career Development International, 18, 216-231.

House, R. J., Hanges, P. J., Ruiz-Quintanilla, S. A., Dorfman, P. W., Javidan, M., Dickson, M., \& Gupta, V. (1999). Cultural influences on leadership and organizations: Project GLOBE. Advances in Global Leadership, 1, 171-233. 
Howell, A., Kirk-Brown, A., \& Cooper, B. K. (2012). Does congruence between espoused and enacted organizational values predict affective commitment in Australian organizations. The International Journal of Human Resource Management, 23, 731-747.

Infeld, D. L., Adams, W. C., Qi, G., \& Rosnah, N. (2010). Career values of public administration and public policy students in China, Malaysia and the United States. International Journal of Public Administration, 33, 800-815.

Jin, J., \& Rounds, J. (2011). Stability and change in work values: A meta-analysis of longitudinal studies. Journal of Vocational Behavior, 80, 326-339.

Johnson, M. K. (2001). Change in job values during the transition to adulthood. Work and Occupations, 28, 315-345.

Johnston, L. D., Bachman, J. G., O'Malley, P. M., \& Schulenberg, J. (2004). Monitoring the future: A continuing study of American youth (12th-grade survey). Ann Arbor, MI: Inter-University Consortium for Political and Social Research.

Kaiser, H. F. (1970). A second generation little-jiffy. Psychometrika, 35, 401-415.

Katsikas, E., \& Panagiotidis, T. (2011). Student status and academic performance: An approach of the quality determinants of university studies in Greece. Studies in Educational Evaluation, 37, 152161.

Leuty, M. E., \& Hansen, J. C. (2011). Evidence of construct validity for work values. Journal of Vocational Behavior, 79, 379-390.

Lub, X., Bijvank, M. N., Bal, P. M., Blomme, R., \& Schalk, R. (2012). Different or alike? Exploring the psychological contract and commitment of different generations of hospitality workers. International Journal of Contemporary Hospitality Management, 24, 553-573.

Lyons, S., Duxbury, L., \& Higgins, C. (2005). An empirical assessment of generational differences in work-related values. Paper presented at the Administrative Sciences Association of Canada Conference. Toronto, ON, Canada.

Lyons, S. T., Higgins, C., \& Duxbury, L. (2010). Work values: Development of a new three dimensional structure based on confirmatory smallest space analysis. Journal of Organizational Behavior, 31, 969-1002.

Lyons, S. T., \& Kuron, L. (2013). Generational differences in the workplace: A review of the evidence and directions for future research. Journal of Organizational Behavior, 35, 139-157.

Lyons, S., Ng, E. S. W., Schweitzer, L., \& Kuron, L. K. J. (2012). Intergenerational differences in work values, career anchors and organizational mobility. Proceedings of the International Society for the Study of Organizational and Work Values Conference, June 24-27, Goa, India.

Ma, Z., Liang, D., Erkus, A., \& Tabak, A. (2012). The impact of group-oriented values on choice of conflict management styles and outcomes: An empirical study in Turkey. The International Journal of Human Resource Management, 23, 3776-3793.

Macedo, K. C. (2012). Valores profissionais da Geração Y: um estudo sobre a Geração Y e os princípios orientadores em sua vida no trabalho. Porto Allegre: Universidade federal do Rio grande do sul - UFRGS (Federal University of Rio Grande do Sul).Manhardt, P. J. (1972). Job orientation of male and female college graduates in business. Personnel Psychology, 25, 361-368. 
Mannheim, K. (1952). Essays on the sociology of knowledge. London: Routledge \& Kegan Paul.

Mboko, S. (2011). Towards an explanation of the growth in young entrepreneur activities: A cross country survey of work values of college students. Journal of Marketing Development and Competitiveness, 5, 108-118.

Mencl, J., \& Lester, S. W. (2014). More alike than different what generations value and how the values affect employee workplace perceptions. Journal of Leadership \& Organizational Studies, doi:1548051814529825

Murphy, W. M. (2012). Reverse mentoring at work: Fostering cross-generational learning and developing millennial leaders. Human Resource Management, 51, 549-573.

Ng, E. S., Schweitzer, L., \& Lyons, S. T. (2010). New generation, great expectations: A field study of the millennial generation. Journal of Business and Psychology, 25, 281-292.

Nunnally, J. C. (1978). Psychometric theory. New York, NY: McGraw-Hill.

Parry, E., \& Urwin, P. (2011). Generational differences in work values: A review of theory and evidence. International Journal of Management Reviews, 13, 79-96.

Porfeli, E. J. (2007). Work values system development during adolescence. Journal of Vocational Behavior, 70, 42-60.

Porto, J. B., \& Tamayo, Á. (2007). Estrutura dos valores pessoais: a relação entre valores gerais e laborais. Psicologia: Teoria e Pesquisa, 23(1), 63-70

Real, K., Mitnick, A. D., \& Maloney, W. F. (2010). More similar than different: Millennials in the U.S. building trades. Journal of Business Psychology, 25, 303-313.

Ros, M., Schwartz, S., \& Surkiss, S. (1999). Basic individual values, work values, and the meaning of work. Applied Psychology: An International Review, 48, 49-71.

Rounds, J. B., Dawis, R. V., Lofquist, L. H., \& Weis, D. J. (1981). Manual for the Minnesota importance questionnaire: A measure of vocational needs and values. Minneapolis, MN: University of Minnesota, Department of Psychology.

Schmidt, R. C. (1997). Managing Delphi surveys using nonparametric statistical techniques. Decision Sciences, 28, 763-774.

Schneider, B. (1987). The people make the place. Personnel Psychology, 40, 437-453.

Schwartz, S. H. (1994). Are there universal aspects in the structure and contents of human values? Journal of Social Issues, 50, 19-45.

Shaw, S., \& Fairhurst, D. (2008). Engaging a new generation of graduates. Education and Training, 50, 366-378.

Siegel, S., \& Castellan, N. J. Jr. (1988). Nonparametric statistics for the behavioral sciences. (International Edition). New York, NY: McGraw-Hill.

Sillerud, H. (2011). Generational differences in employee work values: An explorative study in a Norwegian work context. Oslo: Norwegian School of Management. 
Society for Human Resource Management. (2005). SHRM generational differences survey report: A study by the Society for Human Resource Management (SHRM surveys series). Alexandria, VA: Author.

Strauss, W., \& Howe, N. (1991). Generations: The history of America's future, 1584 to 2069. New York, NY: William Morrow.

Super, D. E. (1957). The psychology of careers. New York, NY: Harper \& Row.

Tabachnick, B. G., \& Fidell, L. S. (2007). Using multivariate statistics (5th ed.). Boston, MA: Allyn and Bacon.

Takase, M., Oba, K., \& Yamashita, N. (2009). Generational differences in factors influencing job turnover among Japanese nurses: An exploratory comparative design. International Journal of Nursing Studies, 46, 957-967.

Taylor, J. (2005). The next generation of workers in Australia: Their views on organizations, work and rewards. The International Journal of Human Resource Management, 16, 1919-1933.

Taylor, J. (2012). Managing the new workforce: International perspectives on the millennial generation. In E. S. Ng, S. T. Lyons, \& L. Schweitzer (Eds.), Managing the new workforce: International perspectives on the millennial generation (pp. 20-41). Cheltenham: Edward Elgar.

Ten Brink, B. E. (2004). Psychological contract: A useful concept? Enschede: Print Partners.

Tissen, R. J., Lekanne Deprez, F. R., Burgers, R. G., \& van Montfort, K. (2010). 'Change or hold: Reexamining HRM to meet new challenges and demands': The future of people at work: A reflection on diverging human resource management policies and practices in Dutch organizations. The International Journal of Human Resource Management, 21, 637-652.

Twenge, J. M. (2010). A review of the empirical evidence on generational differences in work attitudes. Journal of Business and Psychology, 25, 201-210.

Twenge, J. M., Campbell, S. M., Hoffman, B. J., \& Lance, C. E. (2010). Generational difference in work values: Leisure and extrinsic values increasing, social and intrinsic values decreasing. Journal of Management, 36, 1117-1142.

Vincent, J. A. (2005). Understanding generations: Political economy and culture in an ageing society. The British Journal of Sociology, 56, 579-599.

Wils, T., Saba, T., Waxin, F. M., \& Labelle, C. (2011). Intergenerational and intercultural differences in work values in Quebec and the United Arab Emirates. Relations industrielles/ Industrial Relations, 66, 445-469.

Zupan, N., Kaše, R., Ras`kovic', M., Yao, K., \& Wang, K. (2013). Getting ready for generation Y joining the workforce: A comparative analysis of work values of Chinese and Slovenian business students. In M. Ras`kovic' (Ed.), Book of proceedings of the 1st China-Central and Eastern Europe (CEE) Conference on Cross-Cultural Dialogue, Education \& Business, October 4-6, Ljubljana, Slovenia.

Zytowski, D. G. (2004). Super's work values inventory [revised user's manual] (p. 16). Adel, IA: National Career Assessment Services. 
Table 1 Work values-based identity of Millennial-age sample across GLOBE cultural clusters

\begin{tabular}{|c|c|c|c|c|}
\hline GLOBE cluster & Study & Millennial-aged Sample & Work Value Instruments & $\begin{array}{l}\text { Work Value Factors } \\
\text { (Mean importance score) }\end{array}$ \\
\hline \multirow[t]{5}{*}{ 1. Anglo } & Chen \& Choi, (2008) & $\begin{array}{l}112 \text { hospitality managers and } \\
\text { supervisors from a U.S. tourist } \\
\text { destination }\end{array}$ & $\begin{array}{l}\text { 45-item Work Values Inventory (SWVI) } \\
\text { Scale: } 1 \text { (Unimportant) to } 5 \text { (Very important) }\end{array}$ & $\begin{array}{l}\text { Comfort \& Security (extrinsic) (13.33) } \\
\text { Personal Growth (intrinsic) (12.98) } \\
\text { Professional Growth (prestige) (12.56) } \\
\text { Work Environment (12.02) }\end{array}$ \\
\hline & $\begin{array}{l}\text { Gursoy, Chi \& } \\
\text { Karadag (2013) }\end{array}$ & $\begin{array}{l}200 \text { employees from a U.S. hotel } \\
\text { chain }\end{array}$ & $\begin{array}{l}25 \text {-item instrument generated from a series of focus group } \\
\text { meetings } \\
\text { Scale: } 1 \text { (Strongly disagree) to } 5 \text { (Strongly agree) }\end{array}$ & $\begin{array}{l}\text { Leadership (3.98) } \\
\text { Work Centrality (3.76) } \\
\text { Work-life Balance (3.37) } \\
\text { Power (3.08) } \\
\text { Non-Compliance (2.67) } \\
\text { Recognition (2.65) } \\
\text { Technology Challenge (2.18) }\end{array}$ \\
\hline & $\begin{array}{l}\text { Mencl \& Lester } \\
\text { (2014) }\end{array}$ & $\begin{array}{l}86 \text { employees of Chamber of } \\
\text { Commerce member organizations } \\
\text { from a Midwestern U.S. city. }\end{array}$ & $\begin{array}{l}10 \text { items drawn from extant work values studies } \\
\text { Scale: } 1 \text { (Not important at all) to } 7 \text { (A must have) }\end{array}$ & $\begin{array}{l}\text { Teamwork (6.34) } \\
\text { Work-life Balance (6.30) } \\
\text { Career advancement opportunities } \\
\text { (6.19) } \\
\text { Training and Development (6.18) } \\
\text { Involvement in Decision-Making (6.15) } \\
\text { Financial Rewards (6.14) } \\
\text { Challenging Work (6.08) } \\
\text { Flexible Work Arrangements (6.00) } \\
\text { Feedback and Recognition (5.73) } \\
\text { Organization Values Diversity (5.69) }\end{array}$ \\
\hline & Real et al, (2010) & $\begin{array}{l}762 \text { employees of U.S. } \\
\text { construction industry }\end{array}$ & $\begin{array}{l}11 \text { items Monitoring the Future study (Johnston et al, 2006) } \\
\text { Scale: } 1 \text { (Strongly disagree) to } 5 \text { (Strongly agree) }\end{array}$ & $\begin{array}{l}\text { Intrinsic Job Features (3.47) } \\
\text { Social Aspects of Work (2.58) }\end{array}$ \\
\hline & $\begin{array}{l}\text { Twenge, Campbell, } \\
\text { Hoffman \& Lance } \\
\text { (2010) }\end{array}$ & $\begin{array}{l}\text { 2,432 US senior high school } \\
\text { students (class of 2006) }\end{array}$ & $\begin{array}{l}23 \text { items from Monitoring the Future study (Johnston et al, } \\
2006) \\
\text { Scale: } 1 \text { (Strongly disagree) to } 5 \text { (Strongly agree) }\end{array}$ & $\begin{array}{l}\text { Intrinsic (3.76) } \\
\text { Altruistic (3.23) } \\
\text { Social (3.16) } \\
\text { Extrinsic (2.81) } \\
\text { Leisure (2.76) }\end{array}$ \\
\hline
\end{tabular}


Lyons, Duxbury \&

Higgins (2005)

*Lyons, Schweitzer Ng \& Kuron (2012)

*Wils, Saba, Waxin

\& Labelle (2011)

*Cennamo \&

Gardner (2008)

Taylor, 2012

2. America

(Latin)

*Macedo (2012)

*Porto \& Tomayo (2007)

3. Arab

*Wils, Saba, Waxin

\& Labelle (2011)

191 Arab students, in United

Arab Emirates

4. Asia

(Confucian)

900 Canadian knowledge workers and university students

87 Canadian students, in Quebec

86 employees of pharmaceutical \& law firms, media corporations $\&$ construction industry in New Zealand

178 Australian participants in a general social survey

83 Brazilian students

995 Brazilian students

*Chen \& Kao (2012)

435 Taiwanese police college

students
22 items from the Lyons Work Values Survey (LWVS)

Scale: 0 (Not at all important) to 7 (Of supreme importance)

25 items from the LWVS

Scale: 1 (Not at all important) to 5 (Absolutely essential)

28 item work values inventory

Scale : 1 (Opposite to my values), 2 ( Not important) 8 (essential to me)

40 -item instrument comprised of items from LWVS and Work Values Questionnaire (WVQ; Elizur, 1984)

Scale: 1 (Not at all important) to 5 (Absolutely essential)

10 items from the Australian Survey of Social Attitudes Scale: 1 (Not at all important) to 5 (Very important)

Escala de Valores Relativos ao Trabalho (EVT; Porto \& Tamayo, 2003)

Scale: 1 (not important at all) to 5 (extremely important)

Escala de Valores Relativos ao Trabalho (Porto \& Tamayo, 2003)

Scale: 1 (Not important at all) to 5(Extremely important)

28 work values inventory

Scale : 1 (Opposite to my values), 2 ( Not important) 8

(Essential to me)

Work Values Scale (WVS; Ros et al., 1999)

Scale: 1 (Strongly disagree) to 5 (Strongly agree)
Social (5.34)

Extrinsic (5.32)

Intrinsic (4.93)

Altruistic(4.89)

Prestige (4.36)

Extrinsic (3.81)

Intrinsic (3.72)

Social/Altruistic (3.50)

Prestige (3.05)

Self-transcendence (6.27)

Openness to change (6.27)

Conservation (6.26)

Self-enhancement (5.22)

Social (4.18)

Intrinsic (3.97)

Freedom (3.92)

Altruism (3.74)

Extrinsic (3.81)

Status (3.65)

Preference for Motivator Factors (4.47)

Public Service Motivation (4.42)

Preference for Hygiene Factors (4.01)

Intrinsic (4.10)

Extrinsic (4.06)

Social (3.50)

Prestige (2.59)

Intrinsic (4.32)

Extrinsic (3.97)

Social (3.51)

Prestige (2.61)

Self-enhancement (4.30)

Conservation (4.25)

Self-transcendence (4.22)

Openness to change (4.14)

Extrinsic (4.43)

Intrinsic (4.33)

Social (3.95)

Prestige (3.55) 
*Takase, Oma \&

Yamasita (2009)

162 Japanese nurses

5. Asia

(Southern)

\section{Europe \\ (Eastern) \\ 7. Europe \\ (Germanic) \\ Rašković, Yao \& \\ Wang (2013) \\ Hirschi (2008)}

Hirschi \& Fischer

Lub et el., 2012
*Zupan, Kaše,

Rašković, Yao \&

Wang (2013)

Infeld, Adams, Qi \&

Rosnah (2010)

281 Chinese students

60 Malaysian public

administration and public policy programs

549 Slovenian students

492 Swiss secondary \& high school students
Work Values Inventory (MWVI; Manhardt, 1972)

Scale: 1 (Not important at all) to 5(Extremely important)

27 items from the LWVS

Scale: 1 (Not at all important) to 5 (Absolutely Essential)

23 items from the LWVS

Scale: 1 (Not very important) to 5 (Extremely important)

27 items from the LWVS

Scale: 1 (Not at all important) to 5 (Absolutely essential)

Work Values Scale (WVS; Ros et al., 1999)

396 German university students

186 employees from 20 hotels in the Netherlands

59 items from Ten Brink's (2004) psychological contract questionnaire
Working conditions (Extrinsic) (3.93)

Social rewards (Social) (3.55)

Professional Privilege (Prestige) (3.19)

Clinical Challenges (Intrinsic) (3.10)

Extrinsic (3.87)

Social (3.82)

Intrinsic (3.08)

Prestige (3.32)

Altruism (Social) (4.43)

Intrinsic (4.32)

Extrinsic (4.25)

Prestige (4.08)

Comradeship (4.08)

New Public Management (3.84)

Extrinsic (3.97)

Intrinsic (3.90)

Social (3.65)

Prestige (3.33)

Intrinsic (3.29)

Extrinsic (3.04),

Social (2.97),

Prestige (2.76)

Openness to change (23.78)

Self-transcendence (22.54),

Self-enhancement (21.99),

Conservation (21.37)

Scale: 1 (Strongly disagree) to 5 (Strongly agree).
Work atmosphere (4.27)

Stimulating job (4.23)

Autonomy (4.15)

Job security (4.13)

Task description (3.97)

Salary (3.79)

Work-life balance (3.78)

Intra-organizational mobility (3.64) 
employees of Norwegian banking industry.
25 items from the LWVS

1 (Not at all important) to 5 (Absolutely essential)

27 statements adapted from prior research

Scale: 1 (Agree), 3 (Neutral), 5(Disagree)

* Included in cross-national comparisons in Table 4

\section{7-item LWV}

Scale: 1 (Highly unlikely) to 6 ( Highly likely)
Content (5.22)

Collegiality(5.01)

Competence (4.84)

Organizational support (4.83)

Working conditions (4.64)

Meaningful work (4.58)

Freedom (4.41)

Status (4.28)

Intrinsic (4.07)

Freedom (3.64)

Social (3.64)

Extrinsic (3.27)

Altruistic (3.02)

Job challenge (1.23)

Economic opportunity (1.25)

Job security (1.44)

Self direction (1.52)

Work influence (1.75)

Social environment (1.78)

Responsibility (2.57) 
Table 2. Exploratory Factor Analysis ( $\mathrm{N}=328)$

\begin{tabular}{|c|c|c|c|c|c|c|c|}
\hline & \multirow[b]{2}{*}{ Mean } & \multirow[b]{2}{*}{ SD } & \multirow[b]{2}{*}{ Intrinsic } & \multicolumn{2}{|c|}{ Factors } & \multirow[b]{2}{*}{ Social } & \multirow[t]{2}{*}{ Communalities } \\
\hline & & & & Extrinsic & Prestige & & \\
\hline Innovation & 5.20 & 1.06 & .808 & & & & 660 \\
\hline Use abilities & 5.05 & 1.05 & .804 & & & & .575. \\
\hline Autonomy & 5.20 & .98 & .708 & & & & .577 \\
\hline Advancement & 5.24 & 1.07 & .679 & & & & .606 \\
\hline Benefits & 4.41 & 1.23 & & .808 & & & .561 \\
\hline Stress avoidance & 4.68 & 1.22 & & .667 & & & .570 \\
\hline Earnings & 4.52 & 1.22 & & .609 & & & .560 \\
\hline Stability & 5.21 & 1.15 & & .605 & & & .549 \\
\hline Authority & 4.48 & 1.12 & & & -.822 & & .663 \\
\hline Decision making & 4.68 & 1.18 & & & -.714 & & .511 \\
\hline Organization & 4.69 & 1.15 & & & -.627 & & .504 \\
\hline Status & 4.80 & 1.12 & & & -.619 & & .512 \\
\hline Owner & 5.02 & 1.03 & & & & .882 & .730 \\
\hline Esteem & 4.93 & 1.09 & & & & .799 & .686 \\
\hline Colleagues & 4.98 & 1.04 & & & & .644 & .572 \\
\hline Interaction & 4.75 & 1.08 & & & & .605 & .505 \\
\hline Eigenvalue & & & 6.567 & 1.716 & 1.404 & 1.288 & \\
\hline$\%$ variance & & & 38.4 & 8.1 & 6.0 & 5.6 & \\
\hline Cronbach $\alpha^{*}$ & & & .855 & .821 & .819 & .855 & \\
\hline
\end{tabular}

Note: Loadings $<.25$ are not shown, ${ }^{*}$ The total scale Cronbach $\alpha$ was .902

Table 3. Means, standard deviations and correlations between study variables

\begin{tabular}{llccccccc}
\hline \hline & $\mathrm{M}$ & $\mathrm{SD}$ & 1 & 2 & 3 & 4 & 5 \\
\hline 1 & Gender (Female) & - & - & & & & & \\
2 & $\begin{array}{l}\text { Employment status } \\
\text { (Student) }\end{array}$ & - & - & $.078^{*}$ & & & & \\
& Intrinsic Work Values & 5.03 & .97 & $.146^{* *}$ & .014 & & & \\
3 & 4.54 & .92 & $.163^{* *}$ & .017 & $.433^{* *}$ & & \\
4 & Extrinsic Work Values & 4.51 & 1.06 & $.151^{* *}$ & -.038 & $.499^{* *}$ & $.473^{* *}$ & \\
5 & Prestige Work Values & 4.74 & .95 & $.176^{* *}$ & -.024 & $.521^{* *}$ & $.457^{* *}$ & $.509^{* *}$ \\
6 & Social Work Values & & & & & & & \\
\hline \hline
\end{tabular}

a 292 males \& 357 females, ${ }^{\text {b }} 310$ employed \& 339 not employed at the time of the study 
Table 4. Spearman Rank Order Correlations among Countries' Mean Value Scores

\begin{tabular}{|c|c|c|c|c|c|c|c|c|c|c|c|c|c|}
\hline & & & 1 & 2 & 3 & 4 & 5 & 6 & 7 & 8 & 9 & 10 & 11 \\
\hline \multirow{2}{*}{ Eastern Europe } & 1 & Greece & & & & & & & & & & & \\
\hline & 2 & Slovenia & .40 & & & & & & & & & & \\
\hline Germanic & 3 & Switzerland & .80 & .80 & & & & & & & & & \\
\hline \multirow[t]{2}{*}{ Europe } & 4 & Germany & .80 & -.20 & .40 & & & & & & & & \\
\hline & 5 & Japan & -.40 & .40 & -.20 & -.80 & & & & & & & \\
\hline \multirow[t]{2}{*}{ Confucian Asia } & 6 & China & .20 & .80 & .40 & -.40 & .80 & & & & & & \\
\hline & 7 & Taiwan & .40 & 1.00 & .80 & -.20 & .40 & .80 & & & & & \\
\hline \multirow[t]{2}{*}{ Middle East } & 8 & UAE & -1.0 & -.40 & -.80 & -.80 & .40 & -.20 & -.40 & & & & \\
\hline & 9 & Canada & .80 & .80 & 1.00 & .40 & -.20 & .40 & .80 & -.80 & & & \\
\hline \multirow[t]{2}{*}{ Anglo } & 10 & Canada (Quebec) & .40 & 1.00 & .80 & -.20 & .40 & .80 & 1.00 & -.40 & .80 & & \\
\hline & 11 & New Zealand & .80 & .20 & .40 & .60 & .00 & .40 & .20 & -.80 & .40 & .20 & \\
\hline \multirow[t]{4}{*}{ Latin America } & 12 & Brazil & .80 & .80 & 1.00 & .40 & -.20 & .40 & .80 & -.80 & 1.00 & .80 & .40 \\
\hline & & Sig. Positive \% & 45.5 & 54.5 & 54.5 & 9.1 & 9.1 & 36.4 & 54.5 & 0.0 & 54.5 & 54.5 & 9.1 \\
\hline & & Sig. Negative \% & 9.1 & 0.0 & 9.1 & 18.2 & 9.1 & 63.6 & 0.0 & 54.5 & 9.1 & 0.0 & 9.1 \\
\hline & & Not Sig.\% & 45.5 & 45.5 & 36.4 & 72.7 & 81.8 & 0.0 & 45.5 & 45.5 & 36.4 & 45.5 & 81.8 \\
\hline
\end{tabular}

Note: coefficients of .80 or higher are considered significant. Studies included in these analyses are denoted by * in Table 1 